\title{
YqiC of Salmonella enterica serovar Typhimurium is a membrane fusogenic protein required for mice colonization
}

\author{
Mariela C Carrica ${ }^{1,2 *}$, Patricio O Craig ${ }^{2}$, Víctor A García-Angulo², Andes Aguirre ${ }^{3}$, Eleonora García-Véscovi ${ }^{3}$, \\ Fernando A Goldbaum ${ }^{2}$ and Silvio L Cravero ${ }^{1}$
}

\begin{abstract}
Background: Salmonella enterica serovar Typhimurium is an intracellular bacterial pathogen which can colonize a variety of hosts, including human, causing syndromes that vary from gastroenteritis and diarrhea to systemic disease.

Results: In this work we present structural information as well as insights into the in vivo function of YqiC, a 99residue protein of S. Typhimurium, which belongs to the cluster of the orthologous group 2960 (COG2960). We found that YqiC shares biophysical and biochemical properties with Brucella abortus BMFP, the only previously characterized member of this group, such as a high alpha helix content, a coiled-coil domain involved in trimerization and a membrane fusogenic activity in vitro. In addition, we demonstrated that YqiC localizes at cytoplasmic and membrane subcellular fractions, that a $S$. Typhimurium yqiC deficient strain had a severe attenuation in virulence in the murine model when inoculated both orally and intraperitoneally, and was impaired to replicate at physiological and high temperatures in vitro, although it was still able to invade and replicate inside epithelial and macrophages cell lines.
\end{abstract}

Conclusion: This work firstly demonstrates the importance of a COG2960 member for pathogen-host interaction, and suggests a common function conserved among members of this group.

\section{Background}

Salmonella enterica is an intracellular facultative anaerobe Gram-negative that infects a variety of hosts, which include mammals, avians and reptiles. In human beings, $S$. enterica causes over 33 million cases of disease worldwide annually, which may vary from gastroenteritis and diarrhea to severe life-threatening systemic disease (typhoid fever) [1]. The outcome of the disease depends on both the serovar of Samonella and the host susceptibility. Salmonella enterica serovar Typhimurium ( $S$. Typhimurium), can infect humans and animals, but causes different syndromes in each host. In humans, Salmonella produces enterocolitis, but in mice it causes a systemic illness that resembles human typhoid fever. Because of this, $S$. Typhimurium is widely used as a model organism to study the

\footnotetext{
* Correspondence: mcarrica@leloir.org.ar

'Instituto de Biotecnología, CICVyA-INTA Castelar, Los Reseros y Las Cabañas $s / n$, Buenos Aires, Argentina

Full list of author information is available at the end of the article
}

host-pathogen interactions that contribute to the onset of the systemic disease $[2,3]$.

The pathogenic strategy of $S$. Typhimurium includes penetration of the mucosal barrier, invasion of non-phagocytic cells of the intestinal mucosa and survival and replication inside macrophages of the spleen and liver during the systemic phase. The ability of $S$. Typhimurium to survive to host defense mechanisms and to cause disease has been directly linked to genes encoded in pathogenicity islands, which are large horizontally acquired regions of the chromosome. Of outstanding importance are two type three secretion systems (T3SS), which together with cognate effector proteins are essential for cell invasion, intracellular survival and, therefore, for mice colonization [4]. Besides, factors encoded in the genomic backbone of Salmonella are also important for virulence in the murine model [5-8].

YqiC is a 99-residue protein of $S$. Typhimurium (UniProtKB entry K09806, gene STM 3196) which belongs to 
the cluster of orthologous groups 2960 (COG 2960). This COG includes 322 members (Pfam June 2010), encoded in genomes of pathogenic, non-pathogenic and symbiotic bacteria. In spite of the high conservation of this COG across bacterial species, no description of the in vivo function of any member has been reported. In this work, we carried out microbiological studies which demonstrate that YqiC is required for the pathogenesis of S. Typhimurium in the murine model, since a null mutant is highly attenuated when inoculated both orally and intraperitoneally. We also show that this protein is dispensable for cell invasion and intracellular replication in murine macrophages and human epithelial cell lines, but it is necessary for efficient growth at the mammalian host physiological temperature outside the cells. The microbiological results are complemented by biophysical and biochemical studies. These analyses demonstrate that YqiC shares properties with the recently reported BMFP from Brucella abortus (another member of the COG 2960) which include a trimeric coiled-coil structure and the ability to induce membrane fusion in vitro [9]. The results presented here contribute to elucidate the function of members of the COG 2960 and their biological role.

\section{Results}

\section{S. Typhimurium YqiC is a trimeric protein with a high helical content}

YqiC is a 99-residue protein of S. Typhimurium (UniProtKB entry K09806) which belongs to the cluster of orthologous groups 2960 (COG 2960). The bioinformatic analysis of the primary sequence of YqiC predicts a high helical content (66-77\%) http://www.predictprotein.org, including two helical segments that span the $\mathrm{N}$ - and $\mathrm{C}$-terminal halves of the protein (encompassing residues 4-43 and 49-79, respectively). Both helical segments are amphipathic but only the C-terminal one is predicted to form a coiled-coil structure http://groups.csail.mit.edu/cb/ paircoil/paircoil.html. YqiC secondary structure was experimentally determined by its far UV circular dichroism spectrum (Figure 1), which showed a typical signature of an alpha helical protein. The percentage of helical structure of YqiC, estimated through the analysis of its $C D$ spectra using K2D program (63\%), agrees with the percentage of amino acids involved in the predicted $\mathrm{N}$ - and C-terminal alpha helices.

On the other hand, we studied the oligomeric state of YqiC by chemical cross-linking and static light scattering. Chemical cross-linking of YqiC yielded trimers as the largest products when the amount of cross-linking reagent was increased (Figure 2A). Moreover, analysis of YqiC by static light scattering coupled to size exclusion chromatography showed a single homogeneous peak with a molecular mass of $40.2 \mathrm{kDa}$, in agreement with a trimeric structure (Figure $2 \mathrm{~B}$ ).

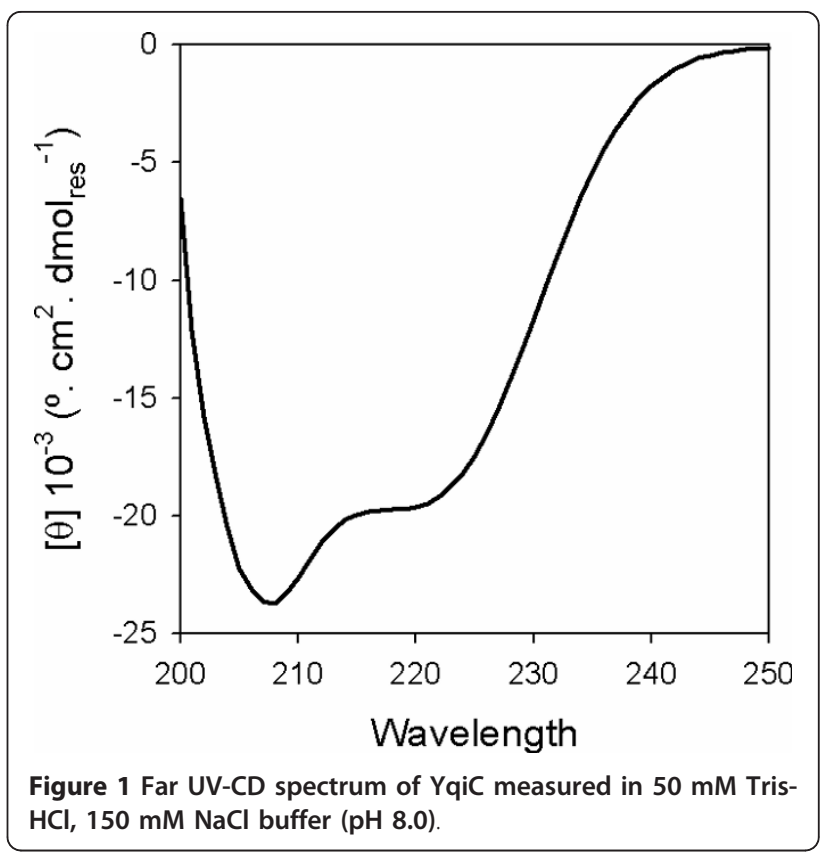

The characteristics described here are similar to the structural features that we have previously reported for Brucella abortus BMFP, which is a member of the COG 2960 that only conserves $22 \%$ sequence identity with YqiC [9].

\section{YiqC promotes membrane fusion in vitro}

As YqiC shares structural properties with BMFP, we investigated if this protein also conserves the membrane fusion activity reported for BMFP [9]. With this aim, we measured the increase in the size and aqueous content mixing of phospholipids vesicles produced after YqiC addition. Changes in the size and aggregation state of vesicles were evaluated by turbidity measurements at $400 \mathrm{~nm}$ whereas the aqueous content mixing was evaluated by measuring the fluorescence of the Tb-DPA complex produced upon fusion of vesicles containing $\mathrm{TbCl}_{3}$ or DPA encapsulated in their aqueous interior phase, and the percentage of mixing was calculated as described in materials and methods. Experiments were carried out on small unilamellar vesicles composed of a mixture of DPPC and DPPA in a 75:25 molar ratio, both at acid or neutral $\mathrm{pH}$. YqiC produced both a significant increase in the turbidity (Figure $3 \mathrm{~A}$ ) and aqueous content mixing (Figure 3B) in the vesicle solutions, mainly at acid $\mathrm{pH}$, after addition of YqiC. These results indicate that $\mathrm{YqiC}$ has a $\mathrm{pH}$-dependent in vitro fusogenic activity.

\section{Subcellular localization of YqiC}

To determine the subcellular localization of YqiC, we performed a mechanical lysis fractionation procedure. A wild type $S$. Typhimurium culture grown to late log 
A

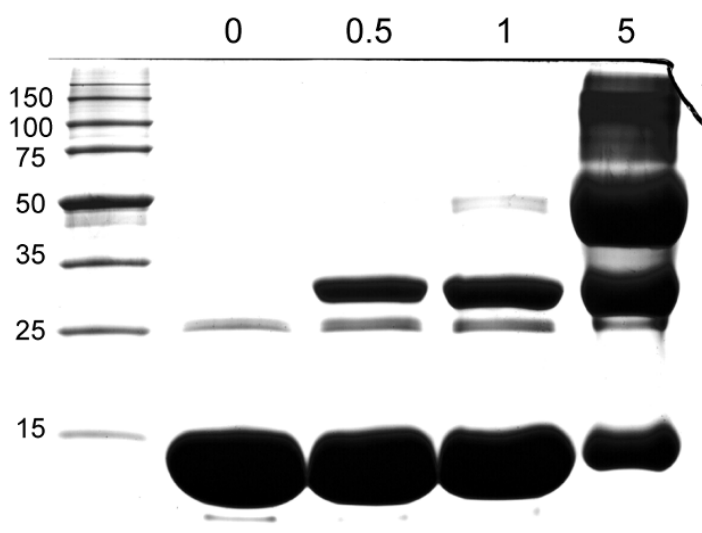

B

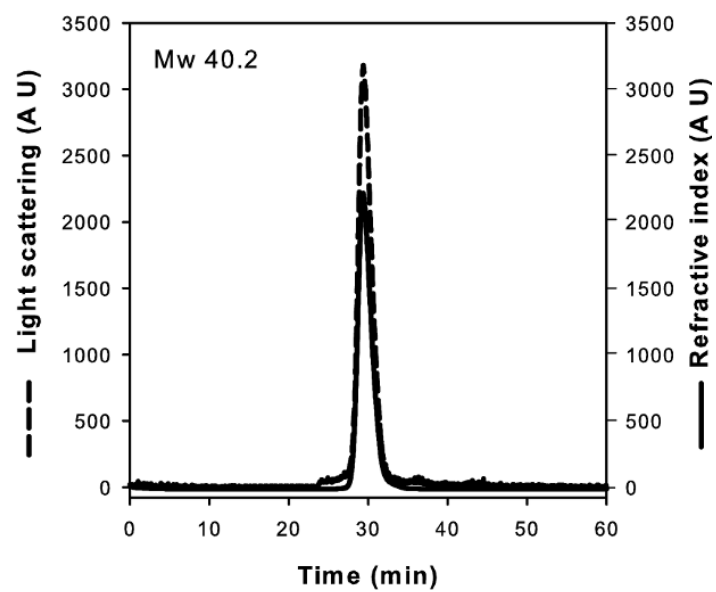

Figure 2 Quaternary structure analysis of YqiC. (A) Chemical cross-linking. Cross-linked products were separated via 15\% SDS-PAGE followed by Coomassie brilliant blue staining. Protein markers are shown in kilodaltons. The numbers $0,0.5,1$, and 5 indicate the millimolar concentrations of ethylene glycol bis (succinimidyl succinate) used. (B) Gel filtration coupled to SLS analysis. The protein was run on a Superdex75 column and eluted with $50 \mathrm{mM}$ Tris- $\mathrm{HCl}, 150 \mathrm{mM} \mathrm{NaCl}$ buffer $(\mathrm{pH}$ 8). The molecular mass of the protein was calculated relating its light scattering at $90^{\circ}$ (dashed line) and refractive index (solid line) signals, and comparison of this value with that obtained for BSA as a standard.

phase was harvested by centrifugation, mechanically disrupted and fractionated by ultracentrifugation. This procedure allows for the separation of bacterial proteins into two fractions: the supernatant, which contains cytoplasmic and periplasmic proteins, and the pellet fraction, which contains the inner and outer membrane proteins. Fractions were then analyzed by immunoblotting using an anti-YqiC polyclonal antibody. YqiC was localized in the two fractions, although lower levels of YqiC were found in the membrane fraction (Figure 4). This result
A

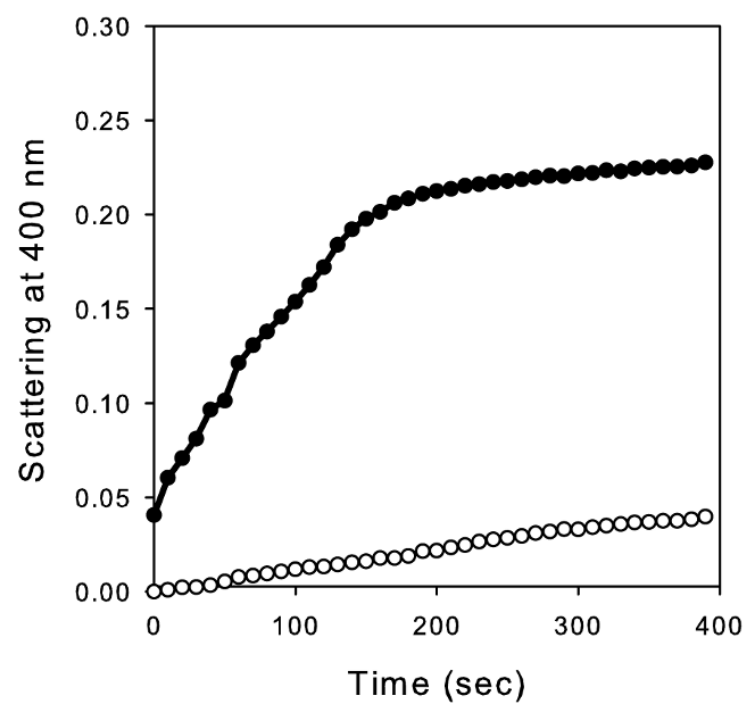

B

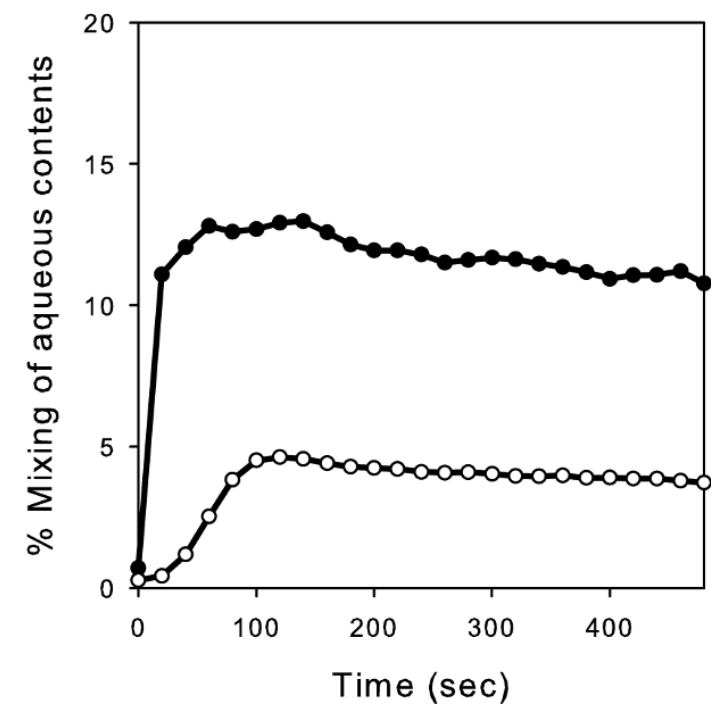

Figure 3 In vitro liposome aggregation and fusion induced by YqiC. (A) Time course of DPPC/DPPA SUV aggregation monitored by light scattering and (B) time course of aqueous content mixing was measured after addition of YqiC protein. Equimolar amounts of terbium (Tb)- and dipicolinic acid (DPA)-loaded SUV were premixed in $10 \mathrm{mM}$ Tris- $\mathrm{HCl}(\mathrm{pH} 8.0), 50 \mathrm{mM} \mathrm{NaCl}$, and $1 \mathrm{mM} \mathrm{EDTA}$. The fluorescence of the Tb(DPA)3 complex formed after the mixing of aqueous contents by protein addition was measured at $545 \mathrm{~nm}$ over incubation time. The measurements were taken in $50 \mathrm{mM}$ Tris- $\mathrm{HCl}$ buffer $\left(\mathrm{pH} 8.0\right.$ ) (open circles) or $50 \mathrm{mM}$ sodium acetate buffer ( $\mathrm{pH} \mathrm{4.0)}$ (close circles) at $25^{\circ} \mathrm{C}$. The liposomes were composed of DPPC and DPPA in a molar ratio of 75:25. The lipid:protein molar ratio was 100: 1 . The data presented are the results of a representative experiment of three independent repetitions. 


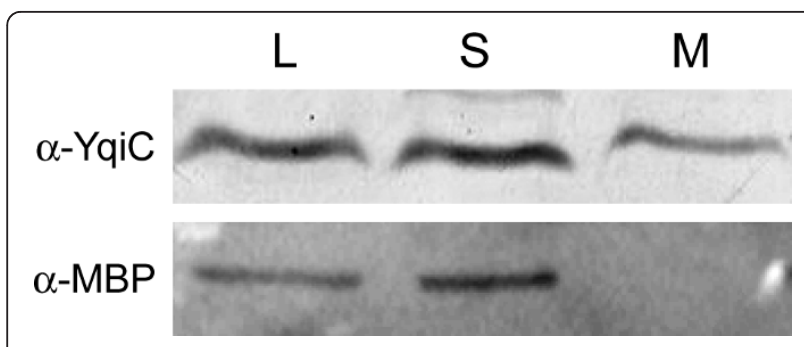

Figure 4 Subcellular localization of YqiC. Whole-cell lysate of S. Typhimurium was fractionated by ultracentrifugation. Samples of the cell lysate $(\mathrm{L})$, the supernatant $(\mathrm{S})$ and the sedimented membrane fraction (M) were analyzed by immunoblotting with anti-YqiC and anti-MBP antiserum. Antibodies against the soluble MBP protein [10] was used as a control for the membrane fraction contamination.

indicated that YqiC is both soluble and membrane associated inside the cell. As a control, we used an antibody against the periplasmic protein MBP [10], which was only detected in the supernatant fraction.

\section{Evaluation of a yqiC defective strain phenotype in vitro}

The in vivo functions of the members of the COG 2960 are unknown. To investigate the role of YqiC protein in S. Typhimurium, we constructed an $S$. Typhimurium ATCC 14028 null mutant in yqiC through allelic exchange. The resulting strain was named $14028 \Delta y q i C::$ CAT. The gene $y q i C$ is encoded divergently to the $r i b B$ gene and convergent to the $g l g S$ gene in the $S$. Typhimurium chromosome. Thus, it appears that $y q i C$ is transcribed as a monocistronic element, and polar effects upon allelic exchange are not expected. The successful elimination of the $y q i C$ gene was corroborated by PCR analysis and a western blot assay of cell lysates of $14028 \Delta y q i C:: C A T$ and its complemented derivative (bearing plasmid pBBR-yqiC, which encodes intact $y q i C$ gene), using a polyclonal antibody raised against YqiC (data not shown). As a first approach to assess the effect of the mutation in the physiology of Salmonella, we tested the effect of temperature in the replication of yqiC mutant strain in LB. No difference in the growth pattern of the yqiC mutant strain compared with the WT was detected at $28^{\circ} \mathrm{C}$ (average generation time $44.9+/$ - 1.4). However, an increased generation time at $37^{\circ} \mathrm{C}$ was observed for $14028 \Delta y q i C:: \mathrm{CAT}$, where the average generation time was $22.5+/-0.7 \mathrm{~min}$ utes for S. Typhimurium 14028 and 48 minutes for 14028 $\Delta y q i C:$ :CAT (Figure 5). This difference in growth was enhanced when the strains were incubated at $42^{\circ} \mathrm{C}$, where the average generation time was $30.2+/-0.68$ minutes for the WT strain and $78.9+/-0.7$ minutes for the $\Delta y q i C:$ : CAT mutant strain. At both temperatures, trans complementation with the plasmid encoding $y q i C$ restored the wild-type growth curve pattern to $14028 \Delta y q i C:$ :CAT. These results indicate that the mutation of $y q i C$ affects the ability of $S$. Typhimurium to replicate at physiological and high temperatures. No growth curve pattern alteration was observed for the $14028 \Delta y q i C::$ CAT strain when incubated in $\mathrm{M} 9$ minimal media or acid $\mathrm{LB}(\mathrm{pH}=4.0)$ at $28^{\circ} \mathrm{C}$ (data not shown), which indicates that the $y q i C$ mutant is neither auxotrophic nor acid sensitive.

\section{Survival of the STM-yqiCmutant in cultured cells}

The pathogenicity of $S$. Typhimurium is critically dependent on its ability to infect and multiply into eukaryotic cells. We investigated whether the $14028 \Delta y q i C::$ CAT strain was affected in its ability to invade and survive within cultured eukaryotic cells. J774 murine macrophages

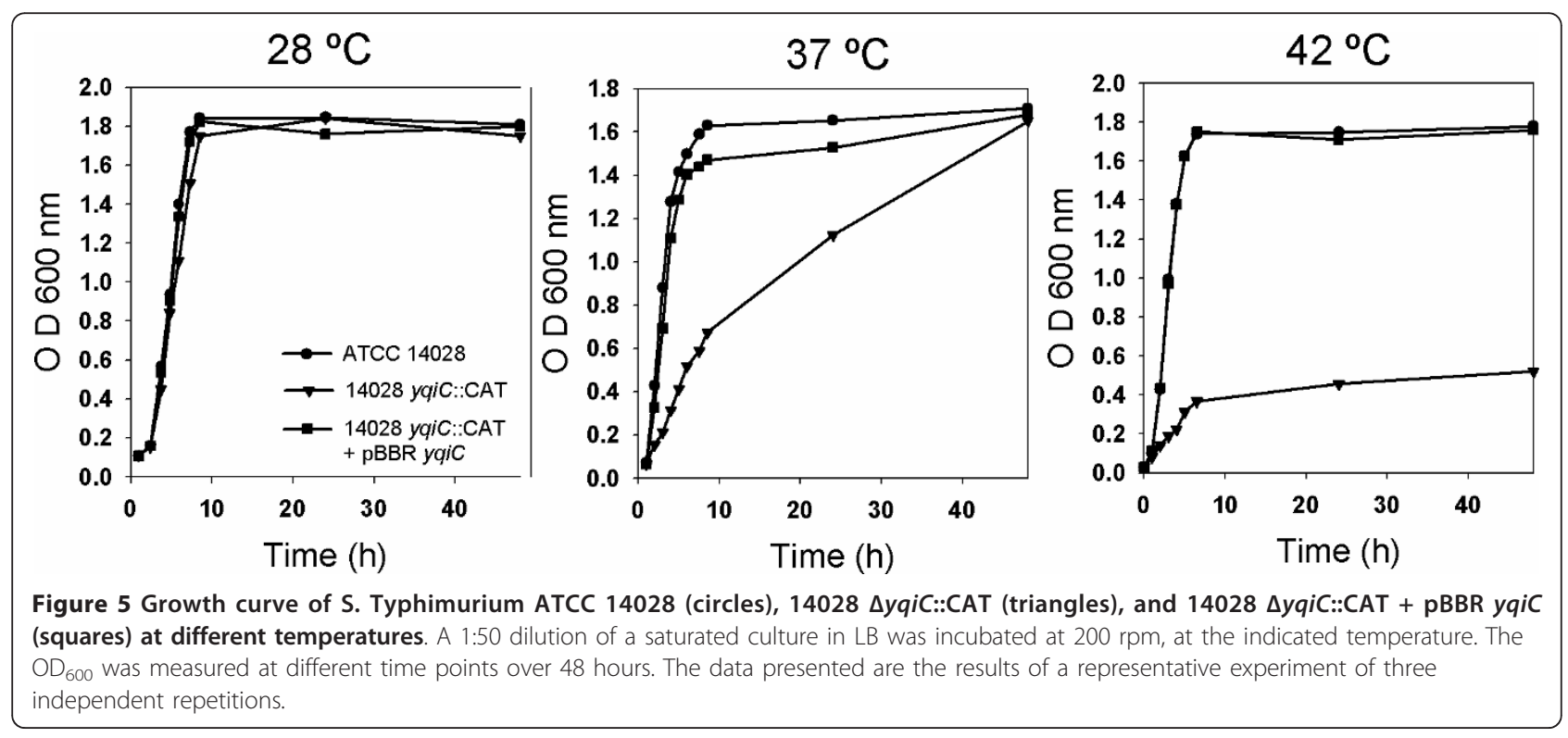


and HeLa human epithelial cell lines were infected with WT S. Typhimurium and $14028 \Delta y q i C:$ CAT strains. As the $14028 \Delta y q i C::$ CAT strain grows defectively at physiological temperature, all strains were grown at $28^{\circ} \mathrm{C}$ prior to infection. Infected cells were kept at $37^{\circ} \mathrm{C}$ and viable intracellular bacteria was determined in cell lysates at 1, 6 and 24 hours after infection. In both cell types, no differences were detected at all time points examined in the CFU recovered from cell lysates infected with the WT or the yqiC mutant strains (Figure 6). This result indicates that the yqiC gene does not contribute to neither Salmonella entry nor intracellular survival in the cell types assayed.

\section{Role of S. Typhimurim YqiC in virulence}

In spite of the clear effect of the yqiC mutant strain on growth at $37^{\circ} \mathrm{C}$, we did not observe any defect in colonizing and surviving inside in vitro cultured eukaryotic cells grown at $37^{\circ} \mathrm{C}$. Thus, we evaluated the virulence of the yqiC mutant in the murine model. To this aim, we performed oral infections with $S$. Typhimurium ATCC 14028, $14028 \Delta y q i C:$ :CAT and $14028 \Delta y q i C::$ CAT transcomplemented with yqiC in BALB/c mice. As illustrated in Figure 7, no survival was registered by day 20 in mice inoculated with WT strain. However, the yqiC mutant showed complete attenuation in virulence, as all mice infected with this strain survived along the 30-day period of the experiment. The yqiC gene provided in trans fully complemented the $14028 \Delta y q i C:$ CAT phenotype, causing $100 \%$ mice death by day 19 . In addition, we determined the LD50 of S. Typhimurium ATCC 14028 and $14028 \Delta y q i C:$ :CAT in mice inoculated intraperitoneally as described in Materials and methods. A dramatic increase in the LD50 was observed in the yqiC defective strain $\left(>5 \times 10^{5} \mathrm{CFU}\right)$, as compared with the WT (10100 CFU) (Table 1). Together, these results clearly show that YqiC is required for $S$. Typhimurium virulence in the murine infection model.

\section{Discussion}

In this work we have characterized the YqiC protein of S. Typhimurium. YqiC shares common structural and biochemical characteristics with its previously reported orthologous BMFP protein of Brucella abortus [9], although these proteins share only $22 \%$ of sequence identity and Brucella spp and Salmonella are phylogenetically distant bacteria. The common structural characteristics between YqiC and BMFP, namely high alpha helix content, coiled coil C-terminal and amphipathic alpha helix N-terminus, are also predicted by bioinformatics analysis for other proteins of the COG 2960 (such as those encoded by Escherichia coli, Shewanella oneidensis, Legionella pneumophila, Xanthomonas campestris, Pseudomonas aeruginosa, Bordetella pertussis, Agrobacterium tumefaciens, Sinorhizobium meliloti and Rhodopseudomonas palustris). This structural conservation strongly suggests a common function for the members of this COG.

In addition, we demonstrated that YqiC has membrane fusogenic activity, like BMFP and other trimeric coiledcoil and/or amphipathic proteins [11,12]. This activity is higher at acidic $\mathrm{pH}$. A similar fusogenic activity at low $\mathrm{pH}$ was observed for B. abortus BMFP (unpublished data). The fusogenic activity could be relevant as many processes that involve bacterial or host cell membrane fusion events are important for pathogenic bacteria to successfully establish host infection. In this regard, both $S$. Typhimurium and B. abortus penetrate the cell by phagocytosis, and reside within a host vacuole that rapidly undergoes acidification. This drop in the $\mathrm{pH}$ serves as a signal for the expression of bacterial factors that alter intracellular membrane traffic in order to set their replicative niche [13-15]. The improved YqiC activity at low $\mathrm{pH}$ could indicate that this protein is active at the vacuolar stage of the bacterial infection. It is interesting to highlight that YqiC shares structural similarity with

\section{J774}

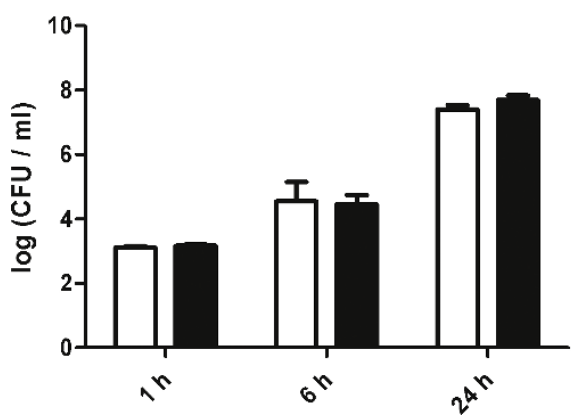

HeLa

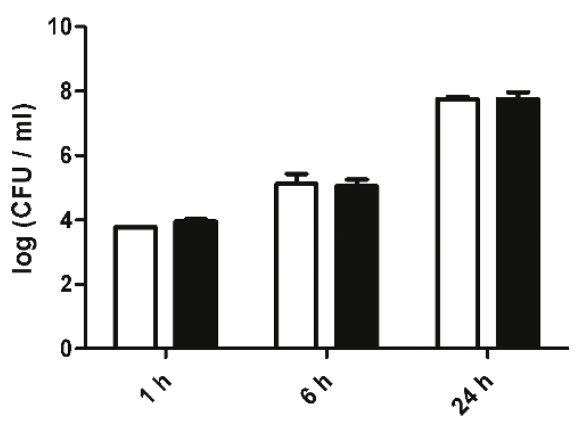

Figure 6 Invasion and intracellular survival of S. Typhimurium strains in cultured cells. S. Typhimurium ATCC 14028 (open bars) and 14028 $\triangle$ yqic::CAT mutant (filled bars) recovered from lysates of $\mathrm{J} 774$ murine macrophages (A) or human epithelial HeLa cells (B). The number of viable bacteria from cell lysates was determined 1, 6 and 24 hours post infection as described in Materials and methods. The reported value is the media of duplicates of a representative experiment $+/$ - standard deviation. 


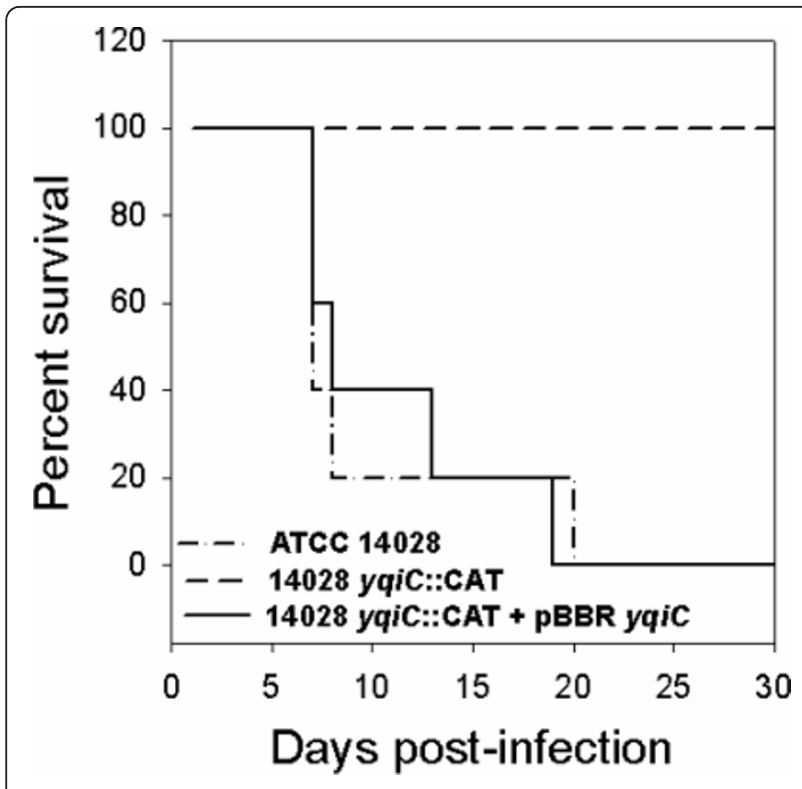

Figure 7 yqiC is essential for virulence in mice. BALB/C mice were orally infected with $1 \times 10^{5} \mathrm{CFU}$ of wild-type $\mathrm{S}$. Typhimurium ATCC 14028, 14028 syqiC::CAT or $14028 \triangle$ yqiC::CAT + pBBR-yqiC. The survival of infected mice over time is shown.

S. Typhimurium-SipB protein, as both are predominantly alpha helical in aqueous solution and have a coiled-coil domain involved in trimerization [16]. SipB is an effector protein essential for Salmonella invasion secreted through the SPI-1-encoded T3SS and was the first bacterial protein reported to display membrane fusogenic activity [16], however the function of this membrane fusogenic activity in the bacterial pathogenesis has not been clearly defined [17]. The activity of YqiC may be required during the interaction of Salmonella with the host cell to hijack membrane trafficking pathways. This would probably be accomplished by competitive inhibition, mimicking eukaryotic membrane fusogenic proteins, such as the SNAREs (given the structural similitude with these proteins) and inhibiting lysosomal fusion with the Salmonella-containing vacuoles. Current work is addressing whether YqiC is translocated to the host cell.
Alternatively, the YqiC-membrane fusogenic activity could be required during the biogenesis of bacterial outer membrane vesicles (OMV), which are spherical bilayered structures liberated from the outer membrane in Gram negative bacteria [18]. OMV act as delivery vesicles for bacterial toxins into host cells, promote quorum sensing, are involved in stress response, inhibit phagosome-lysosome fusion during bacterial growth within macrophages and are important constituents of the matrix of Gram-negative and mixed bacterial biofilm [19-23]. To date, the machinery that cause vesicle formation remains elusive but it may be expected that a protein with membrane fusion activity could be involved in this process $[18,24]$. In this regard, in spite of the lack of a signal peptide or transmembrane domains we demonstrated that YqiC can be localized both soluble and associated to membranes. This localization pattern was also observed for B. abortus BMFP (unpublished data). Subcellular localization pattern of YqiC may be in tune with its hypothetical function in biogenesis of OMV, as soluble and membrane-bound states of YqiC can be related to transient associations of this protein with the outer membrane. At this point, is interesting to note that OMV produced by Shigella flexneri contain IpaB, a SipB homologue which also displays membrane fusion activity $[25,26]$. Accordingly, many of the bacterial species conserving an YqiC homolog have been shown to generate OMV [18,27]. Further work is needed to investigate the possible role of YqiC in the biogenesis of OMV.

The in vivo importance of YqiC was demonstrated by the fact that this protein is necessary for $S$. Typhimurium virulence in the murine model, as an yqiC mutant strain was unable to kill mice within the period of time assayed and had a significantly higher LD50. The basis for this attenuation in virulence may be related to the observed defect to grow at physiological temperature in vitro. Temperature represents a common environmental challenge that microorganisms should be able to sense and respond to in order to survive [28]. Many other single gene mutations produce temperature-sensitive, virulence-attenuated Salmonella strains. Examples include

Table 1 Determination of LD50 of S.Typhimurium strains in mice

\begin{tabular}{ccc} 
& \multicolumn{2}{c}{$\begin{array}{c}\text { Number of dead mice/Number of infected mice } \\
\text { (Mean of days to death) } \\
\text { S. Typhimurium 14028 } \Delta y q i C:: \text { CAT }\end{array}$} \\
\hline Dose (CFU/mouse) & S. Typhimurium ATCC 14028 & $0 / 7$ \\
$1 \times 10^{1}$ & $3 / 7(6)$ & $0 / 7$ \\
$1 \times 10^{2}$ & $7 / 7(6.7)$ & $0 / 6$ \\
$1 \times 10^{3}$ & $6 / 6(5.5)$ & $0 / 6$ \\
$1 \times 10^{4}$ & $6 / 6(4.5)$ & $0 / 6$ \\
\hline
\end{tabular}

Groups of the indicated number of mice were inoculated intraperitoneally with different doses of S. Typhimurium ATCC or S. Typhimurium strain and survival was recorded for up to 30 days. 
$\operatorname{smp} A$, which encodes for an outer membrane lipoprotein, $u s p A$, which encodes for an universal stress response protein and the genes for DegP and DegQ proteases [29-31]. Interestingly, temperature sensitivity could not be the only factor responsible for the virulence attenuation observed for the $y q i C$ mutant, as this strain was still able to invade and replicate inside macrophages and epithelial cell lines incubated at $37^{\circ} \mathrm{C}$. These phenotypes may be due to differences in the metabolic status and environmental conditions affecting bacteria replication in rich media under laboratory conditions and inside the eukaryotic cell.

\section{Conclusion}

We have demonstrated in this work that $S$. Typhimurium YqiC shares structural and biochemical characteristics with $B$. abortus BMFP, in spite of their relatively low sequence identity. Thus, members of the COG 2960 may accomplish a conserved function among phylogenetically distant bacteria. This function may be necessary to display full virulence. This seems to be the case, as in a parallel work we observed virulence attenuation when analyzing a $B$. abortus BMFP-defective strain (Cravero et $a l$, unpublished work). This work is the first demonstration of the in vivo importance of a member of the COG 2960. However, future research is necessary to clarify the physiological processes in which the membrane fusogenic activity and possibly other unknown functions of YqiC are required.

\section{Methods}

\section{Ethics Statement}

All experiments involving animals have been approved by the ethics committee of the Instituto Nacional de Tecnologia Agropecuaria (INTA) where they were conducted. This ethics committee works according with the National Institutes of Health Guide for the Care and Use of Animals Laboratory [32].

\section{Bacterial Strains and Growth Conditions}

For this study, we used the WT Salmonella enterica serovar Typhimurium strain ATCC 14028. Bacterial strains were grown in Luria-Bertani (LB) or M9 minimal medium containing casamino acids and glucose. Appropriate antibiotics were added to the following final concentrations: $100 \mu \mathrm{g} \mathrm{ml}^{-1}$ ampicillin, $25 \mu \mathrm{g} \mathrm{ml}^{-1}$ kanamycin, and $10 \mu \mathrm{g} \mathrm{ml}^{-1}$ chloramphenicol.

\section{DNA Manipulation and plasmid construction}

Plasmid pET24D-YqiC (encoding full length YqiC protein) was generated by polymerase chain reaction (PCR) from Salmonella enterica serovar Typhimurium ATCC 14028 chromosome DNA using primers 5'-AACCATGGTTGACCCGAAAAAAATT-3' and 5'-TTCTCGAGCTCTT
GTTGTGGATCGAC-3' and the product was cloned in NcoI and XhoI sites of pET24D vector (Novagen) in frame with the T7 promoter. The product included a sixhistidine tag fused to the $\mathrm{C}$-terminal end of the protein. To construct plasmid pBBR-yqiC, a $1210 \mathrm{bp}$ fragment containing yqiC gene and flanking regions from $S$. Typhimurium was amplified by PCR using the primers 5'-GGCTTCAATGGTCACGGTAA-3' and 5'-GCAATATGGACGAGGAGCATC-3'. The resulting fragment was then cloned into the EcoRI site of the broad-hostrange plasmid pBBR1MCS1 [33].

\section{Expression and Purification of Recombinant Protein}

pET24D plasmid encoding the sequence of yqiC was transformed in E. coli BL21 (lambda DE3). The cells were grown in $\mathrm{LB}$ at $37^{\circ} \mathrm{C}$ to an OD 600 of 0.5 and induced with $1 \mathrm{mM}$ isopropyl $\beta$-D thiogalactoside (IPTG) for $4 \mathrm{~h}$. Cells were harvested by centrifugation at $3000 \times g$ for $20 \mathrm{~min}$, resuspended in binding buffer (Qiagen), and disrupted by sonication with a probe tip sonicator. Total cell lysate was centrifuged at $14000 \times g$ for $30 \mathrm{~min}$ to remove non-soluble protein, cell debris, and unbroken cells. Binding and elution from nickel nitrilotriacetic acid-agarose resin were carried out under native conditions according to the manufacturer's instructions (Qiagen). Eluted proteins were dialyzed against phosphate-buffered saline ( $\mathrm{pH}$ 7.4). Proteins were assayed with a Coomassie blue-based staining solution.

\section{Vesicle Preparation}

Phospholipids were purchased from Avanti Polar Lipids (Birmingham, AL) and from Sigma. L- $\alpha$-dipalmitoylphosphatidylcholine (DPPC) and L- $\alpha$-dipalmitoylphosphatidic acid (DPPA) were cosolubilized in chloroform in different molar ratios, dried under $\mathrm{N}_{2}$, resuspended in buffer $50 \mathrm{mM}$ Tris- $\mathrm{HCl} \mathrm{pH} 8.0$ or $50 \mathrm{mM}$ sodium acetate $\mathrm{pH} 4.0$ and sonicated to yield small unilamellar vesicles (SUV).

\section{Chemical Cross-Linking}

Purified YqiC was cross-linked with ethylene glycol bis (succinimidylsuccinate) (EGS) (Sigma) used at concentrations of $0.5,1.0$, and $5.0 \mathrm{mM}$. The reactions were carried out for $30 \mathrm{~min}$ at room temperature in phosphate-buffered saline and stopped by addition of $50 \mathrm{mM}$ Tris- $\mathrm{HCl}, \mathrm{pH}$ 8.0. Cross-linked products were analyzed by SDS-PAGE.

\section{Determination of the Molecular Weight by Static Light Scattering}

The average molecular weight $(M w)$ of $\mathrm{YqiC}$ was determined on a Precision Detector PD2010 light scattering instrument tandemly connected to a high-performance liquid chromatography system and an LKB 2142 
differential refractometer. The sample was loaded on a Superdex 75 column and eluted with PBS buffer. The $90^{\circ}$ light scattering and refractive index signals of the eluting material were analyzed with Discovery32 software, supplied by Precision Detector. The $90^{\circ}$ light scattering detector was calibrated using bovine serum albumin $(66.5 \mathrm{kDa})$ as a standard.

\section{Circular Dichroism Spectroscopy}

The circular dichroism (CD) spectra of YqiC in the farUV region (250-200 $\mathrm{nm}$ ) were measured on a Jasco J-810 spectrophotometer using quartz cuvettes with a path length of $0.1 \mathrm{~cm}$. The CD spectra were analyzed with K2D software http://www.ogic.ca/projects/k2d2/ [34] to evaluate the secondary structure content.

\section{Turbidity Assay}

Turbidity measurements were taken on a Multiskan Spectrum double-beam spectrophotometer (Thermo Electro Corp.) by using $1 \mathrm{~cm}$ matched silica cuvettes at $400 \mathrm{~nm}$. The SUV concentration was $250 \mu \mathrm{M}$. The lipid: protein ratio for the turbidity assays was kept at 50:1.

\section{Vesicle Internal Content Mixing}

Small unilamellar vesicles were prepared containing either $5 \mathrm{mM}$ terbium chloride, $50 \mathrm{mM}$ sodium citrate, $10 \mathrm{mM}$ Tris/ $\mathrm{HCl}$ ( $\mathrm{pH} 7.4)$, or $50 \mathrm{mM}$ sodium dipicolinate (DPA) and $10 \mathrm{mM}$ Tris- $\mathrm{HCl}(\mathrm{pH}$ 7.4). The vesicles concentration was $100 \mu \mathrm{M}$. In both cases, no encapsulated material was removed by gel filtration of the vesicles using Sephadex G-25 (Pharmacia) equilibrated with iso-osmolar $50 \mathrm{mM}$ $\mathrm{NaCl}, 1 \mathrm{mM}$ EDTA, and $10 \mathrm{mM}$ Tris- $\mathrm{HCl}$ (pH 7.4). Zero percent and $100 \%$ fluorescence (aqueous content mixing) were taken as the intrinsic fluorescence intensity of the $\mathrm{Tb} / \mathrm{DPA}$-labeled liposome mixture and the fluorescence obtained after vesicle lysis with $0.2 \% n$-dodecyl maltoside in assay buffer without EDTA as described by Duzgunes et al [35]. Fluorescence measurements were carried out at $25^{\circ} \mathrm{C}$ using a Molecular Devices SpectroMAX GeminiEM spectrofluorometer. The extent of vesicles aqueous content mixing was determinated according to the following equation:

$\%$ aqueous content mixing $=\left[\left(\mathrm{F}_{\mathrm{t}}-\mathrm{F}_{0}\right) /\left(\mathrm{F}_{\max }-\mathrm{F}_{0}\right)\right] \times 100$

Where $F_{0}$ is the value of initial fluorescence of the vesicles, $F_{t}$ is the value of fluorescence after incubation for $t$ minutes with the protein, and $F_{\max }$ is the value of fuorescence after addition of $0.2 \%$ of $n$-dodecyl maltoside.

\section{Immunoblot analysis}

Polyclonal anti-YqiC primary antibodies were obtained in mice immunized with purified YqiC. Immobilon-NC
Transfer Membranes (Millipore) containing transferred proteins were blocked in 5\% nonfat milk PBS for $1 \mathrm{~h}$, and incubated with either a 1:200 dilution of polyclonal anti-YqiC or 1:200 anti-MBP mouse polyclonal antibodies. The secondary antibody used was goat anti-mouse IgG (Fc Specific) Peroxidase Conjugate (Sigma) at 1:1000 dilution. Positive signals were detected with Chemiluminiscent ECL Plus Western Blotting Detection System (Amersham Biosciences) on a Storm Image and Detection system (Molecular Dynamics).

\section{Cell fractionation}

Wild-type S. Typhimirium strain was grown in $80 \mathrm{~mL}$ LB medium to an OD600 of 1 and harvested by centrifugation at $4000 \times \mathrm{g}$. The pellet was resuspended in $3 \mathrm{ml} 20 \mathrm{mM}$ Tris- $\mathrm{HCl}$ (pH 8.0) and $150 \mathrm{mM} \mathrm{NaCl}$ and mechanically lysed in a FastPrep instrument. Cell debris was removed by centrifugation for $30 \mathrm{~min}$ at $8000 \times \mathrm{g}$. Subsequently, membranes were sedimented by ultracentrifugation for $1 \mathrm{~h}$ at $100,000 \times \mathrm{g}\left(4^{\circ} \mathrm{C}\right)$. The pellet was resuspended in a volume equivalent to that of the supernatant. Samples from the supernatant and pellet fraction were analyzed by immunoblotting.

\section{Construction of yqiC S. Typhimurium mutant strain}

Elimination of the yqiC gene was achieved by using Lambda Red-mediated recombination described previously [36]. A lineal DNA fragment that contains the sequence for a chloramphenicol resistance cassette plus flanking regions of yqiC was constructed by PCR using the pair of primers 5'-CGCACTACAATAAGAGCTAACACTTACCAGTTCAGGGAAAGTGTAGGCTGGAGCTGCTTC G-3' and 5'-TGGATCGACTGGCGGAATGGCGGGCGCAGGTTTTACTTCTCATATGAATATCCTCCTTA-3'. $5 \mu \mathrm{g}$ of this construction were introduced into strain LB5010 by electroporation. Chloramphenicol resistant colonies were then verified by PCR using a set of primers that hybridize within the insertion cassette and with an adjacent chromosomal region. Finally, isogenic strain was constructed by P22-mediated transduction of the mutant DNA into S. Typhimurium ATCC 14028. The substitution of the $y q i C$ gene in this strain was verified by PCR and by the lack of expression of YqiC protein using western blot assay. The $S$. Typhimurium $\triangle y q i C:: C A T$ mutant was named $14028 \Delta y q i C:$ :CAT.

\section{Mice infections}

To determine the $50 \%$ lethal dose (LD50) of the $S$. Typhimurium strains used, groups of seven 6-8 weeks old, female, BALB/c mice were infected intraperitoneally (i.p.) with serial 10 -fold dilutions (from $1 \times 10^{1}$ to $1 \times 10^{5} \mathrm{CFU}$ ) of the wild type $S$. Typhimurium ATCC 14028 or 14028 $\Delta y q i C:: \mathrm{CAT}$, and deaths were recorded for 28 days. For 
oral infections with $S$. Typhimurium ATCC 14028, 14028 $\Delta y q i C:: \mathrm{CAT}$ and $14028 \Delta y q i C:: \mathrm{CAT}$ trans-complemented with pBBR-yqiC, mice were starved for food and water for $4 \mathrm{~h}$. Following starvation, $10^{5} \mathrm{CFU}$ of each specific strain in $100 \mu \mathrm{l}$ of phosphate-buffered saline ( $\mathrm{pH}$ 7.4) were administered by oral gavage to each mouse. Survival of infected mice was recorded over 30 days. Inoculation doses were verified by serial dilution and plating into LB agar.

\section{Cell invasion and intracellular replication}

J774 murine macrophages and HeLa human epithelial cell lines were seeded at a density of $2 \times 10^{5}$ cells per well in 24-well culture plates. Stationary phase cultures of $S$. Typhimurium ATCC 14028, $14028 \Delta y q i C::$ CAT and complemented strain $14028 \Delta y q i C:: \mathrm{CAT}+\mathrm{pBBR}-$ yqiC grown at $28^{\circ} \mathrm{C}$ overnight were added to the cells at a multiplicity of infection (MOI) of 10 . Culture plates containing infected cells were centrifuged at $1000 \mathrm{rpm}$ for $10 \mathrm{~min}$ and incubated at $37^{\circ} \mathrm{C}$ for $30 \mathrm{~min}$ to allow bacterial uptake and invasion. The extracellular bacteria were removed by washing thrice with PBS and incubating with $100 \mu \mathrm{g} / \mathrm{ml}$ gentamycin for $1 \mathrm{~h}$. Thereafter, the cells were incubated with $25 \mu \mathrm{g} / \mathrm{ml}$ gentamycin for the rest of the experiment. After 1, 6 and $24 \mathrm{~h}$, the cells were lysed with $1 \mathrm{~mL}$ of $0.1 \%$ Triton-X 100 per well and bacterial counts were determined by plating serial dilutions of the lysates on LB agar plates with appropriate antibiotic followed by incubation at $28^{\circ} \mathrm{C}$.

\section{Acknowledgements}

This work was supported by grants from INTA (National project 472-AESA 2581) and Howard Hughes Medical Institute to Dr. Fernando Goldbaum (HHMI). The authors are researchers or are recipient of a fellowship from CONICET.

\section{Author details}

${ }^{1}$ Instituto de Biotecnología, CICVyA-INTA Castelar, Los Reseros y Las Cabañas s/n, Buenos Aires, Argentina. ${ }^{2}$ Fundación Instituto Leloir (IIBBA-CONICET), Av. Patricias Argentinas 435, Buenos Aires, Argentina. ${ }^{3}$ Instituto de Biología Molecular y Celular de Rosario, Consejo Nacional de Investigaciones Científicas y Técnicas, Departamento de Microbiología, Facultad de Ciencias Bioquímicas y Farmacéuticas, Universidad Nacional de Rosario, Suipacha 531, S2002LRK Rosario, Argentina.

\section{Authors' contributions}

MCC, CPO, GAV and AA carried out the molecular biology, protein studies, mice experiments and participated in the draft of the manuscript. GFA, GVE and CSL conceived the study and participated in its design and coordination and drafted the manuscript. All authors read and approved the final manuscript.

Received: 24 January 2011 Accepted: 9 May 2011 Published: 9 May 2011

\section{References}

1. Chuang $\mathrm{CH}$, Su LH, Perera J, Carlos C, Tan BH, Kumarasinghe G, So T, Van PH, Chongthaleong A, Hsueh PR, Liu JW, Song JH, Chiu CH: Surveillance of antimicrobial resistance of Salmonella enterica serotype Typhi in seven Asian countries. Epidemiol Infect 2009, 137:266-269.

2. Hansen-Wester I, Hensel M: Salmonella pathogenicity islands encoding type III secretion systems. Microbes Infect 2001, 3:549-559.
3. Coburn B, Grassl GA, Finlay BB: Salmonella, the host and disease: a brief review, Immunol Cell Biol. 2007, 85:112-118.

4. McGhie EJ, Brawn LC, Hume PJ, Humphreys D, Koronakis V: Salmonella takes control: effector-driven manipulation of the host. Curr Opin Microbiol 2009, 12:117-124.

5. Rodriguez-Morales O, Fernandez-Mora M, Hernandez-Lucas I, Vazquez A, Puente $J$, Calva E: Salmonella enterica serovar Typhimurium ompS1 and ompS2 mutants are attenuated for virulence in mice. Infect Immun 2006, 74:1398-1402.

6. Chatfield SN, Dorman CJ, Hayward C, Dougan G: Role of ompR-dependent genes in Salmonella typhimurium virulence: mutants deficient in both ompC and ompF are attenuated in vivo. Infect Immun 1991, 59:449-452.

7. Su JH, Chung YC, Lee HC, Tseng IC, Chang MC: Ferrous iron-binding protein Omb of Salmonella enterica serovar Choleraesuis promotes resistance to hydrophobic antibiotics and contributes to its virulence. Microbiology 2009, 155:2365-2374.

8. Bjur E, Eriksson-Ygberg S, Aslund F, Rhen M: Thioredoxin 1 promotes intracellular replication and virulence of Salmonella enterica serovar Typhimurium. Infect Immun 2006, 74:5140-5151.

9. Carrica Mdel C, Craig PO, Alonso Sdel V, Goldbaum FA, Cravero SL: Brucella abortus MFP: a trimeric coiled-coil protein with membrane fusogenic activity. Biochemistry 2008, 47:8165-8175.

10. Bassford PJ Jr, Silhavy TJ, Beckwith JR: Use of gene fusion to study secretion of maltose-binding protein into Escherichia coli periplasm. J Bacteriol 1979, 139:19-31.

11. Dutch RE, Jardetzky TS, Lamb RA: Virus membrane fusion proteins: biological machines that undergo a metamorphosis. Biosci Rep 2000, 20:597-612.

12. Parente RA, Nir S, Szoka FC Jr: pH-dependent fusion of phosphatidylcholine small vesicles. Induction by a synthetic amphipathic peptide J Biol Chem 1988, 263:4724-4730.

13. Celli J: Surviving inside a macrophage: the many ways of Brucella. Res Microbiol 2006, 157:93-98.

14. Bakowski MA, Cirulis JT, Brown NF, Finlay BB, Brumell JH: SopD acts cooperatively with SopB during Salmonella enterica serovar Typhimurium invasion. Cell Microbiol 2007, 9:2839-2855.

15. Beuzon CR, Meresse S, Unsworth KE, Ruiz-Albert J, Garvis S, Waterman SR, Ryder TA, Boucrot E, Holden DW: Salmonella maintains the integrity of its intracellular vacuole through the action of SifA. Embo J 2000, 19:3235-3249.

16. Hayward RD, McGhie EJ, Koronakis V: Membrane fusion activity of purified SipB, a Salmonella surface protein essential for mammalian cell invasion. Mol Microbiol 2000, 37:727-739.

17. Collazo CM, Galan JE: The invasion-associated type III system of Salmonella typhimurium directs the translocation of Sip proteins into the host cell. Mol Microbiol 1997, 24:747-756.

18. Mashburn-Warren LM, Whiteley M: Special delivery: vesicle trafficking in prokaryotes. Mol Microbiol 2006, 61:839-846.

19. Kesty NC, Mason KM, Reedy M, Miller SE, Kuehn MJ: Enterotoxigenic Escherichia coli vesicles target toxin delivery into mammalian cells. Embo J 2004, 23:4538-4549.

20. Mashburn LM, Whiteley M: Membrane vesicles traffic signals and facilitate group activities in a prokaryote. Nature 2005, 437:422-425.

21. McBroom AJ, Kuehn MJ: Release of outer membrane vesicles by Gramnegative bacteria is a novel envelope stress response. Mol Microbiol 2007, 63:545-558.

22. Fernandez-Moreira E, Helbig JH, Swanson MS: Membrane vesicles shed by Legionella pneumophila inhibit fusion of phagosomes with lysosomes. Infect Immun 2006, 74:3285-3295.

23. Schooling SR, Beveridge TJ: Membrane vesicles: an overlooked component of the matrices of biofilms. J Bacteriol 2006, 188:5945-5957.

24. Deatherage BL, Lara JC, Bergsbaken T, Rassoulian Barrett SL, Lara S, Cookson BT: Biogenesis of bacterial membrane vesicles. Mol Microbiol 2009, 72:1395-1407.

25. Kadurugamuwa $\lrcorner \mathrm{L}$, Beveridge TJ: Delivery of the non-membranepermeative antibiotic gentamicin into mammalian cells by using Shigella flexneri membrane vesicles. Antimicrob Agents Chemother 1998, 42:1476-1483.

26. Hume PJ, McGhie EJ, Hayward RD, Koronakis V: The purified Shigella IpaB and Salmonella SipB translocators share biochemical properties and membrane topology. Mol Microbiol 2003, 49:425-439. 
27. Kuehn MJ, Kesty NC: Bacterial outer membrane vesicles and the hostpathogen interaction. Genes Dev 2005, 19:2645-2655.

28. Ono S, Goldberg MD, Olsson T, Esposito D, Hinton JC, Ladbury JE: H-NS is a part of a thermally controlled mechanism for bacterial gene regulation. Biochem J 2005, 391:203-213.

29. Mo E, Peters SE, Willers C, Maskell DJ, Charles IG: Single, double and triple mutants of Salmonella enterica serovar Typhimurium $\operatorname{deg} \mathrm{P}(\mathrm{htr} \mathrm{A})$, degQ (hhoA) and degS (hhoB) have diverse phenotypes on exposure to elevated temperature and their growth in vivo is attenuated to different extents. Microb Pathog 2006, 41:174-182.

30. Liu WT, Karavolos MH, Bulmer DM, Allaoui A, Hormaeche RD, Lee JJ, Khan CM: Role of the universal stress protein UspA of Salmonella in growth arrest, stress and virulence. Microb Pathog 2007, 42:2-10.

31. Oliver SP, Gillespie BE, Ivey SJ, Lewis MJ, Johnson DL, Lamar KC, Moorehead H, Dowlen HH, Chester ST, Hallberg JW: Influence of prepartum pirlimycin hydrochloride or penicillin-novobiocin therapy on mastitis in heifers during early lactation. J Dairy Sci 2004, 87:1727-1731.

32. Sciences CoL: Guide for the care and use of laboratory animals. Washington, D. C; 1996.

33. Kovach ME, Phillips RW, Elzer PH, Roop RM, Peterson KM: pBBR1MCS: a broad-host-range cloning vector. Biotechniques 1994, 16:800-802.

34. Andrade MA, Chacon P, Merelo JJ, Moran F: Evaluation of secondary structure of proteins from UV circular dichroism spectra using an unsupervised learning neural network. Protein Eng 1993, 6:383-390.

35. Duzgunes N, Wilschut J: Fusion assays monitoring intermixing of aqueous contents. Methods Enzymol 1993, 220:3-14.

36. Datsenko KA, Wanner BL: One-step inactivation of chromosomal genes in Escherichia coli K-12 using PCR products. Proc Natl Acad Sci USA 2000, 97:6640-6645

doi:10.1186/1471-2180-11-95

Cite this article as: Carrica et al: YqiC of Salmonella enterica serovar Typhimurium is a membrane fusogenic protein required for mice colonization. BMC Microbiology 2011 11:95.

\section{Submit your next manuscript to BioMed Central and take full advantage of:}

- Convenient online submission

- Thorough peer review

- No space constraints or color figure charges

- Immediate publication on acceptance

- Inclusion in PubMed, CAS, Scopus and Google Scholar

- Research which is freely available for redistribution

Submit your manuscript at www.biomedcentral.com/submit
Biomed Central 